\title{
Aspects of the Social Organization and Trajectory of the R Project
}

by John Fox

\begin{abstract}
Based partly on interviews with members of the $\mathrm{R}$ Core team, this paper considers the development of the $\mathrm{R}$ Project in the context of open-source software development and, more generally, voluntary activities. The paper describes aspects of the social organization of the $\mathrm{R}$ Project, including the organization of the R Core team; describes the trajectory of the R Project; seeks to identify factors crucial to the success of $\mathrm{R}$; and speculates about the prospects for $\mathrm{R}$.
\end{abstract}

\section{Introduction}

This paper describes aspects of the R Core team; briefly traces the trajectory of the R Project; discusses the development and organization of the R Project; considers the reasons for the success of R; and speculates about its prospects for continued success. The paper is based on semi-structured interviews conducted during 2006 and 2007 with most members of the R Core team, whom I will occasionally quote in the paper; on publicly available archival sources; and on participant observation in the R Project, as a user, package developer, author, and - more recently - a member of the R Foundation.

The paper is not a complete consideration of the social organization of the $\mathrm{R}$ Project in that it does not systematically address interactions among members of the R Core team, nor between the Core team and package developers and users, nor among developers and users, all of which would be the proper subject of a more complete account. Nevertheless, I do try to identify key aspects of the social design of the $\mathrm{R}$ Project, particularly with respect to their contributions to the success of $R$ and to its future.

\section{What is problematic about open- source software development?}

Why do people contribute to open-source projects such as R? Is this behaviour purely altruistic, or are there rewards - tangible and otherwise - to opensource development? Raymond (2001c), for example, suggests that the open-source development community constitutes a "gift culture" in which the currency is reputation; he also argues (Raymond, 2001d) for the economic rationality of businesses that support open-source development. Similar arguments about the potential rationality of participation in open-source projects are advanced by Weber (2004).
Although I will address the question of motivation briefly (and although it is raised repeatedly by economists), it is not an issue unique to open-source software development: After all, people participate in a wide variety of voluntary organizations. There is a large and venerable literature in sociology on voluntary associations (for reviews, see Smith, 1975, and Knoke, 1986), much of it focusing on participation, and more recent work in the area addressing the "social capital" accruing to communities as a consequence of participation in voluntary organizations (following Putnam, 1995).

Winchester (2003, p. 215) writes of the unpaid volunteers who contributed meticulous work to the monumental Oxford English Dictionary:

[W] do not really know why so many people gave so much of their time for so little apparent reward. And this is the abiding and most marvelous mystery of the enormously democratic process that was the Dictionary - that hundreds upon hundreds of people, for motives known and unknown, for reasons both stated and unsaid, helped to chronicle the immense complexities of the language that was their own, and that they dedicated in many cases ... years upon years of labour to a project of which they all, buoyed by some set of unfathomable and optimistic notions, insisted on becoming a part.

With a few changes in specifics, much the same can be said of participation in the R Project - both by members of the Core team and by others.

Participation in open-source software projects is in this sense no different from participation in other voluntary organizations, such as coaching a children's ice-hockey team or contributing to the $O E D$. When asked about their motivation for working on the $\mathrm{R}$ project, members of the $\mathrm{R}$ Core team responded with conventional reasons for participating in a voluntary association:

- To satisfy a sense of obligation (with a hint of rational self-interest).

[M]y feeling is that I gain great benefit from open-source software. This is tremendously valuable to me, being able to use all of these other tools, and I feel both a moral and practical obligation to contribute back into this sea of tools that are, I 
think, very important for the development of our profession.

And, in another case:

$[P]$ robably more than half of what I've done for the $\mathrm{R}$ Project is not because I needed it, but because I thought that the R Project needed it. There are relatively few things in $R$ that I have done that I needed

- To do intrinsically rewarding work.

[It's] very satisfying ...to work on a day-to-day basis with people with whom one has common interests and can get a lot of pleasure from working with.

- To contribute to the broader public good.

One of the nicest sort of things [is that] other people in the Philippines or Bolivia or Mexico ... can have a world class statistical software system [when] they could never afford any of the commerical systems.

In another case:

[Y]ou want to actually contribute something for the greater good. I mean that's why we do this stuff in the hope that it is actually of importance to some people, [that] it's going to change things.

What seems to me most problematic about opensource software development, however, is how the work gets done. Traditionally, software was developed by rigidly hierarchical organizations that reflected the perceived necessity for an overall design of a software project and a division of labour in its execution. Despite the ideology of open-source development as a "bazaar" (Raymond, 2001b), an opensource software project of any complexity must (like the $O E D)$ come to grips with the problems of social organization, including direction and division of labour, if it is to succeed. After all, different parts of the software have to combine in a functional whole.

\section{The $\mathrm{R}$ Core team}

The $\mathrm{R}$ Core team is responsible for the development of the basic R software and for the infrastructure that supports its continued development and distribution. As most readers of this journal are likely aware, the R Project began around 1990 as the informal endeavour of Robert Gentleman and Ross Ihaka, who were then both at Auckland University in New
Zealand. The initial development of $\mathrm{R}$ is described in Ihaka and Gentleman (1996). Several other individuals became part of the project, in the sense of having write-access to the $\mathrm{R}$ source code, over the next five or six years, but the organization of the project remained informal. Then, in 1997, this structure was formalized in the creation of an R Core group with nine members, a number that has subsequently grown to 19 (see Figure 1).

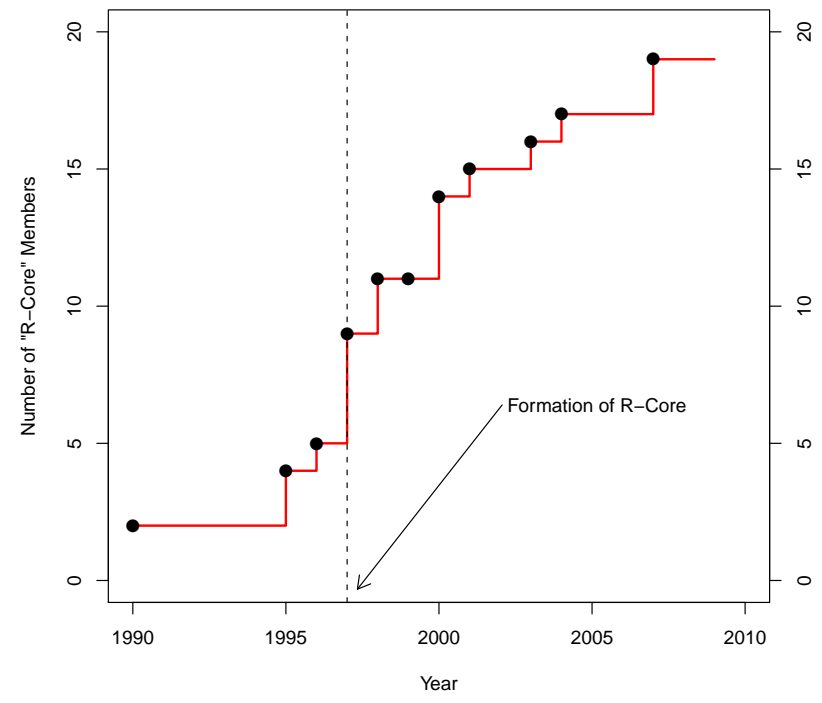

Figure 1: Growth of the R Core team. Points represent changes in membership. Source of data: Interviews and personal communications with members of R Core.

Open-source software projects vary a great deal in their organization: Some are undertakings of large corporations, such as Sun (Open Office), IBM (the Eclipse interactive software development environment), or Google (the Android smart-phone platform). Many open-source projects, such as the Linux operating system, have strongly hierarchical structures, and some, such as Perl, revolve around a central individual. (See, e.g., Fogel, 2006, for a prescriptive treatment of the organization of open-source software projects, along with the ideological writings of Raymond, 2001a, and Stallman, 2002.) Although I haven't formally surveyed the many existing opensource projects, the R Project is apparently unusual in its flat formal organization of independent volunteers. This structure has attracted a remarkably talented and competent group of individuals, but, as I will argue later in this paper, it poses challenges for moving the R Project forward.

Although there are few formally differentiated roles among members of the $\mathrm{R}$ Core team, there is a fuzzy division of labour. Certain members of $R$ Core, for example, are responsible for maintaining the versions of $\mathrm{R}$ for different operating systems, 
and other members for maintaining the CRAN package archive. The development of this division of labour was essentially accidental, particularly in the early stages of the $\mathrm{R}$ Project. More recently, several members of the $\mathrm{R}$ Core team were recruited at least partly because their skills and expertise complemented those of then-current members of the Core group.

A loose, more-or-less naturally developed division of labour serves the day-to-day needs of the $R$ Project - that is, routine tasks such as preparation and dissemination of a new release, making marginal improvements to $\mathrm{R}$, or fixing bugs that are discovered in the software - but it does not account for new directions in the development of $R$, particularly when decisions are controversial.

According to my interviews with $\mathrm{R}$ Core members, the Core group operates according to what I would describe as a modified-consensus model. An issue is discussed, for example, at occasional faceto-face meetings of $\mathrm{R}$ Core members and more frequently by email. An attempt is made to reach a consensus, but consensus is not always possible. In such cases, frequently nothing is done to move the issue forward, and development simply does not take place. In other instances, development is pushed forward preemptively by one or a small number of $R$ Core members who are willing simply to implement a change. One example that came up repeatedly in my interviews was the implementation of internationalization in $\mathrm{R}$. As one member of $\mathrm{R}$ Core put it to me, "[We have] a system that [is] democratic but the person who [is] going to do the work [gets] more votes than anybody else." In such cases, the silence of other R Core members connotes consent - or at least acquiescence. Another R Core member said, "[C]onsensus could be as simple as nobody objecting." Except with respect to membership in the Core group, formal votes do not occur.

A number of members of $\mathrm{R}$ Core referred to a more formal process by which at least some larger innovations are first described in written proposals:

[F]or more complex things, people understand they need to write a request for comments, which they do, and that generates its own thread; and on the basis of that, the proposal is either modified or, very rarely, things have to be abandoned.

Table 1 attempts to summarize several key aspects of the organization of the R Project during three "stages" of its development: (1) an initial stage, during which $\mathrm{R}$ was the exclusive project of Gentleman and Ihaka, with some student participation; (2) a transitional stage during which several other developers were recruited to the project; and (3) a continuing mature stage during which the $\mathrm{R}$ Project has been guided by a formally constituted Core team.

Figure 2 points out another characteristic of the
$\mathrm{R}$ Core group - that activity in the R svn (versioncontrol) archive is highly unequal, and that the level of inequality has increased since 1997. I hasten to add that this activity, assessed as number of "commits" to the archive by each member of R Core, is measured imperfectly: Individual "commits" to the archive can represent vastly different amounts of code, and the contribution of an $\mathrm{R}$ Core member to the project may not be reflected in changes to the svn archive. Nevertheless, the Gini coefficient for commits by R Core members has risen from 0.67 to 0.85 in a little more than a decade, and the proportion of commits by the single most active individual (not the same person, by the way, through this period) reached a high of 0.73 in 2007.

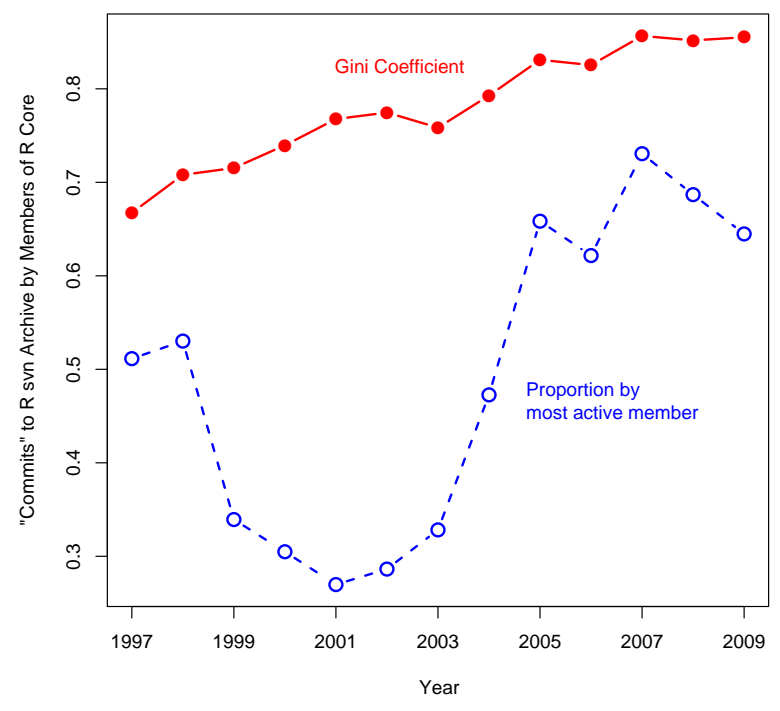

Figure 2: There is a high level of inequality among $\mathrm{R}$ Core members in the number of "commits" to the $\mathrm{R}$ svn archive. Source of data: http://developer. r-project.org/.

\section{The trajectory of the $\mathrm{R}$ Project}

Writing about $\mathrm{R}$ in a book published in 2002, I pointed approvingly to the "more than 100 contributed packages available on the $\mathrm{R}$ Web site ... many of them prepared by experts in various areas of applied statistics." Comparing R to S-PLUS, I said that, "I believe that the current development of $\mathrm{R}$ is more dynamic." There are now nearly 2000 contributed packages on CRAN. The left panel of Figure 3 shows that the growth in CRAN packages has been approximately exponential - the linear correlation between the log of the number of packages and time exceeds 0.99; a plot of residuals, however, in the right panel of Figure 3, shows that the rate of growth has been slowing recently.

Although it is more difficult to assess how widely 


\begin{tabular}{|l|lll|}
\hline & & & Stage \\
\hline Approximate Dates & Initial & Transitional & Core \\
Recruitment & $1990-94$ & $1994-97$ & $1997-$ \\
Division of labour & some student participation & demonstrated interest & semi-purposive, by invitation \\
Hierarchy & none & developing & semi-formal \\
Principal Mode of Cooperation & none & direct collaboration & original developers, contributors differential participation \\
Planning & none & implicit voluntarism & partly distinct roles + voluntarism \\
Decision-Making & joint & individual & partial \\
Resolution of Disagreements & discussion & largely unnecessary & modified consensus \\
principal goal & personal development & reproduce and improve S & discussion, preemption, avoidance \\
\hline
\end{tabular}

Table 1: Stages in the development of the R Project.
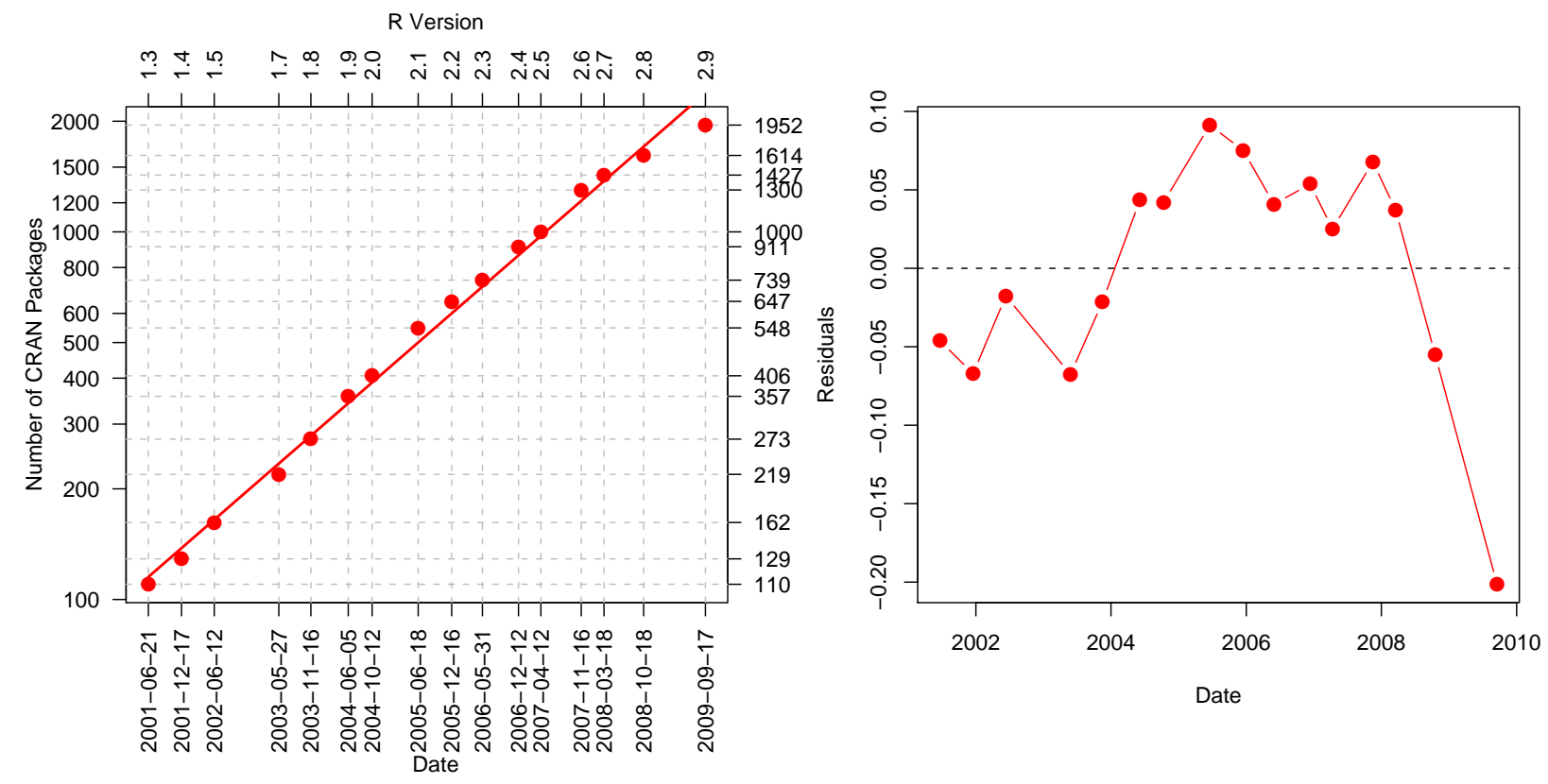

Figure 3: The number of packages on CRAN (left panel) has grown roughly exponentially, with residuals from the exponential trend (right panel) showing a recent decline in the rate of growth. The number of packages for $\mathrm{R}$ version 1.6 is not shown because the count was taken only two days after that for version 1.5, and therefore indicated just one additional package. (An earlier version of the graph in the left panel appeared in Fox, 2008.) Sources of data: https://svn.r-project.org/R/branches/ and (for version 2.9) http://cran.r-project.org/web/checks/check_summary.html. 
$\mathrm{R}$ is used, the anecdotal evidence makes the hypothesis of exponential growth coupled with currently wide use plausible. A recent article in both the print and on-line editions of The New York Times (Vance, 2009) supports the increasing popularity of $R$ - regardless of the merits of the article itself. Likewise, developers of commercial statistical software, such as SPSS and SAS, who find themselves in competition with $\mathrm{R}$, have moved to make $\mathrm{R}$ available from within their products. Figure 4 shows the monthly rate of messages on the r-help, r-devel, and other ("SIG") email lists from 1997 to 2008. After a period of less-than-exponential growth, the growth in the overall number of messages appears once more to be accelerating.

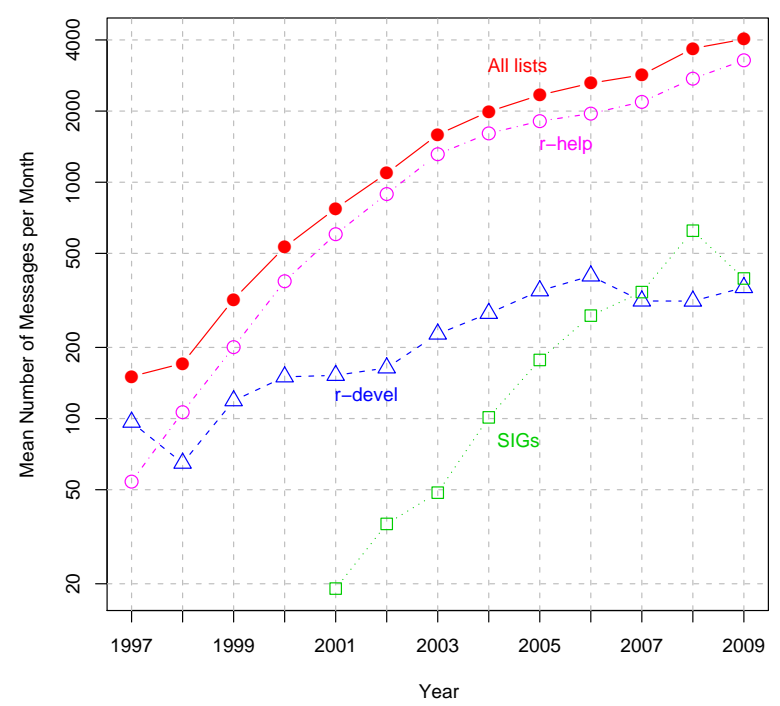

Figure 4: There has been dramatic growth in traffic on the R email lists. Source of data: http://www. r-project.org/mail.html.

\section{Why did the R Project succeed?}

That the R Project has "succeeded" is undeniable, and the members of the R Core team whom I interviewed unanimously endorsed that judgment. This success rests on a number of factors (some of which I have already mentioned):

\section{Open-source development}

The initial developers - Robert Gentleman and Ross Ihaka - opened up the project, eventually forming the $\mathrm{R}$ Core group and releasing $\mathrm{R}$ under the GNU General Public License (GPL). Other software, such as Octave (Eaton et al., 2008) and Lisp-Stat (Tierney, 1990), which followed a different development model focusing on a single key individual, have not gained as wide acceptance. ${ }^{1}$

Partly by accident, but increasingly by design, the $\mathrm{R}$ Project attracted a Core group of immensely talented individuals, including leading figures in statistical computing.

\section{The S language}

After an initial period in which it served mainly to satisfy the curiosity of its creators, the R Project acquired a concrete, if not exclusive, target: roughly to reproduce the functionality of $S$ in a language with essentially similar syntax. ${ }^{2}$

As a corollary to the last point, much of the necessary software beyond the basic R system was already available in S "libraries" (e.g., MASS, Venables and Ripley, 2002; survival, Therneau and Lumley, 2009; nlme, Pinheiro et al., 2009) which could be ported to $R$. As an additional corollary, the $S$ language had substantially penetrated the community of statisticians, and so R had a favourably disposed, strategically important group of potential users.

In comparison to other free statistical software (e.g., Lisp-Stat) $\mathrm{R}$ is relatively easy to use, particu-

\footnotetext{
${ }^{1}$ I base this claim partly on my interviews with members of R Core who had experience with other software. Note that the point is independent of the intentions of the original developers of $\mathrm{R}$ and other software, but is rather meant to be descriptive of the effects of the manner in which they incorporated contributions from other people.

${ }^{2}$ Although this assertion was disputed by a referee, I think that an examination of the contents of the standard R distribution supports it. Moreover, the point came up several times in my interviews; for example,

[T] he rough idea that the R people have had over the years is that the .... so-called Blue Book and ... the so-called White Book are kind of a rough definition of the $S$ language. And so, not necessarily always, but fairly often, if a question comes up about what something should do or how it should be interpreted there's a tendency to go back to those books and look at them.

Another member of R Core said,

$\mathrm{R}$ wasn't created from scratch - well, it was, but there was a model, some members of the core team call it the prototype. So when there were disputes about the way things should work, then the development process was inevitably drawn towards similar behaviour to $\mathrm{S}$, except in cases where the $\mathrm{S}$ behaviour was obviously wrong. ... [C]ompatibility with $\mathrm{S}$ ... became an important design requirement. When $\mathrm{R}$ first started it was ... in many ways quite different.

Just to be clear: I don't mean to claim that R simply or exclusively reproduces S, nor that replicating the functionality of S was an initial goal of the original $\mathrm{R}$ duo of developers. As well, I'm focusing here on the syntax of $\mathrm{R}$ - which is the feature of the language most visible initially to users - as opposed to its semantics, which derive from the Scheme dialect of Lisp (see Ihaka and Gentleman, 1996).

${ }^{3}$ Of course, those previously familiar with Lisp will have little difficulty picking up Lisp-Stat, but a fair comparison assumes a user without this sort of background. My own experience provides some anecdotal support for the assertion: I came to R directly from APL and Lisp-Stat. I also had some prior, superficial exposure to $\mathrm{S}$, had programmed in several different languages starting with Fortran, and used a variety of statistical packages, such as BMDP, Minitab, SPSS, and SAS. It took me at least a couple of months of intensive work
} 
larly for those already familiar with $S .{ }^{3}$ I'm aware that there are frequent remarks about the "steep learning curve" associated with $\mathrm{R}$, but I think that these complaints have point-and-click statistical software and not competing statistical programming environments as their primary reference.

\section{The $R$ package system}

The package system, introduced early in the life of $R$, permits individuals to participate in the development of $\mathrm{R}$ without the direct intervention of the $\mathrm{R}$ Core group. In a sense, the package system - like version control - is a technological solution to a social problem: how to invite, motivate, and coordinate the activity of hundreds of volunteers without overwhelming the resources of the Core team. As one $\mathrm{R}$ Core member put it,

[T] he package system allows us to take advantage of lots of people without having to find some way of getting consensus from them. ... [The package system] wasn't designed with that social purpose in mind but I think that it's been critical in $\mathrm{R}$ being successful.

The package system provides a variety of integrative functions, including quality control; enforcement of standards; provision of a common documentation format, which itself has certain novel and noteworthy features (e.g., the incorporation of executable examples); and convenient distribution.

In addition to help files, the package system supports the provision of automatically-compiled longer documents, termed "vignettes." More generally, R has cross-fertilized the development of literate programming tools for statistics, most notably Sweave (described in Leisch, 2002, 2003).

Because $\mathrm{R}$ is programmable, it permits users to develop software for their own use. The package system encourages them then to share this software with others and, to a limited extent, facilitates recognition for software development. This process allows $\mathrm{R}$ to grow in a natural, organic manner. Although $\mathrm{R}$ is not unique in providing a programming environment for statistical applications, nor in providing a mechanism for sharing code, the $\mathrm{R}$ package system is particularly well worked out. This general point, moreover, extends to the the core developers as well, whose work on $\mathrm{R}$ is partly motivated by their research interests, both statistical and substantive. The availability of a wide variety of contributed packages, in turn, enhances the attractiveness of $\mathrm{R}$ to a diverse group of users, including those who do not write their own programs
The package system also serves at least partly to circumvent disputes that might otherwise fracture the $\mathrm{R}$ Project. Although this route has its limitations, one can innovate in packages without making changes directly to the basic $\mathrm{R}$ system. As has been pointed out to me, however, the same might be said of other open-source software projects that support packages, and some of these projects - for example, Emacs and Linux - have forked. But the general point seems sound: A successful package system raises the threshold for forking an open-source project.

\section{Other considerations}

Several other factors have contributed to R's success:

- As is common in open-source software projects, the $\mathrm{R}$ Core group has successfully leveraged information technology, both to coordinate its own activities (e.g., by version control) and to involve others in the project (e.g., via e-mail lists, package automation, and distribution via the Internet). Many of the members of R Core, however, stressed the importance of periodic face-to-face meetings among the core developers. One said, for example, that face-toface meetings were "crucial," and continued,

[Y]ou can sort out details by email, but you cannot thrash out general policy, and so having a meeting every year or two is really important to get it together and get general ideas sorted out.

- $\mathrm{R}$ runs on all widely used computational platforms (Windows, Mac OS X, and Linux/Unix systems).

- Where R differs from S, it has clearly improved on the latter. Some examples are lexical scoping, the package system, and the introduction of namespaces. Development of new software in $\mathrm{R}$, therefore, has become more attractive than in S-PLUS, even when cost is not an issue.

- And, of course, $\mathrm{R}$ is free, in both of Stallman's (2002) senses - $R$ is available free of cost, and users of $\mathrm{R}$ are free to examine, modify, and redistribute the software.

\section{What are the prospects for $R$ ?}

Many of the factors leading to the initial success of $\mathrm{R}$ are of continued relevance. In addition, $\mathrm{R}$ has accumulated a great deal of momentum: It has attracted

to become reasonably comfortable with Lisp, but just a few days to reach a similar level of competence in $\mathrm{R}$ (and I don't think that the transfer from Lisp to $\mathrm{R}$ was very great). Watching inexperienced students coping with Lisp-Stat and $\mathrm{R}$ reinforces this judgment about their relative difficulty. Moreover, a number of the members of R Core made similar points. One said, for example, "I think Lisp-Stat is great, I like it a lot,... [but] I know a fair amount of people, and you probably do too, who just can't relate to the Lisp way of expressing things." 
a large and growing user community and developer base. Indeed, much of the dynamism of $\mathrm{R}$ is now in package development. The visibility of $\mathrm{R}$ has grown, with, for example, the publication of many books that reference $\mathrm{R}$ directly or indirectly. As a consequence, quite a few individuals and organizations now have a substantial investment in R. I have already noted the recent New York Times article on $\mathrm{R}$, and the fact that commercial statistical-software developers have found it advantageous to try to integrate $\mathrm{R}$ in their products.

Nevertheless, several aspects of the social organization of the R Project pose challenges to its continued success.

\section{Decision making and division of labour in R Core}

The decision-making procedures of the $\mathrm{R}$ Core team were perhaps better suited to an earlier stage in the development of the software and to a smaller Core group. At an earlier phase in the development of $R$, so much work needed to be done that direction and coordination were less critical issues than they now appear to be. Moreover, the modified-consensus decision-making procedure of the $\mathrm{R}$ Core team and its dependence on voluntarism have apparently prevented some long-standing issues from being adequately addressed.

Several members of $\mathrm{R}$ Core mentioned this problem to me-although they don't necessarily agree on what the outstanding issues are. For example,

There are several major issues which have been around for a long time. One major issue is how to, how closely to integrate $\mathrm{S} 4$ with "Base $\mathrm{R}$ " .... And then performance is still a major issue ... [We] are gradually moving towards isolating the problems and working on the obstacles, gradually eliminating them. But there's no sort of concerted effort in the sense that we say, "OK, let's all sit together and figure out what the actions are that need to be taken, and let's do an action plan and all that stuff." Development doesn't work along these lines.

With respect to $\mathrm{R}$ infrastructure for handling large data sets, an issue that came up in several interviews, one member of the R Core team remarked,

I think for a lot of the stuff, if you look at the $\mathrm{R}$ development, it happens when someone has the need for it. If it hasn't happened thus far, it's because all the 17 core developers haven't had the specific need for that kind of thing, but eventually it will happen.
Two observations about this last remark: (1) As I explained earlier, a great deal of the activity of members of R Core (e.g., the implementation of internationalization) is not the product of direct need, and so it would clearly be wrong to conclude the the contents of the base $\mathrm{R}$ system simply reflect the needs of the core developers. (2) There are indeed facilities in $\mathrm{R}$ for handling large quantities of data, as reflected, for example, in various interfaces to database-management systems, $R$ packages for handling massive genomic data sets, and packages, such as the biglm (Lumley, 2009a) and survey (Lumley, $2009 \mathrm{~b}$ ) packages, that are specifically designed to deal with large problems. Nevertheless, I believe that the basic point is a valid one: At least in naive use, $R$ users often encounter memory issues, as evidenced by the frequency with which such issues are raised on the r-help email list.

Similarly, another member of R Core remarked,

I have more ambitious plans for package mechanisms, and threading is looming large on the horizon all the time, but there's a lot of resistance to making major changes, and that inhibits me from doing a lot of stuff there.

He attributed the resistance to two factors: a "need to maintain the user base," and the lack of time among members of R Core to do "long term scheduling."

There is another side to the coin of modifiedconsensus decision-making that has been pointed out to me as well: Requiring consensus, or at least acquiesence, avoids the implementation of half-baked solutions to problems.

I have already noted the apparently unequal division of labour among the members of the $\mathrm{R}$ Core group. There is, therefore, a potential overdependence upon a few key individuals, and no clear plan for succession if these individuals were for some reason to drop out or seriously to curtail their activities. As one member of $\mathrm{R}$ Core put it to me, "[T]here are several small groups of people who, if they fairly simultaneously dropped out, I suspect that it would be very difficult to keep the $\mathrm{R}$ Project running."

\section{Tension between innovation and back- wards compatibility}

An advantage that the $\mathrm{R}$ Core team has relative to commercial software developers is that they are not as tightly constrained by their "customers." For example, commercial developers risk alienating their customers if they fail to maintain strict backwards compatibility of their software. Such constraints on $\mathrm{R}$ are not entirely absent, however, and several members of $\mathrm{R}$ Core (one of whom was quoted above) mentioned them to me in the interviews that I con- 
ducted. Speaking of partial name matching, for example, one R Core member told me:

I think that was a bad design decision. I don't think that's ever going to change, though. I think it's too widely used, even though it should change, and ... the pain would be worth the gain, ... [but] it won't happen.

And more generally,

I don't think [R] will change radically. I would like it to change, I would like to introduce new capabilities, ... but I think it's too big now to have those accepted.

\section{Negotiating CRAN}

The current organization of CRAN — essentially a flat, alphabetized list of nearly 2000 packages — may not be sustainable. It is already difficult for users to navigate the package archive to find resources within it. The problem, however, isn't inherent to CRAN itself, but rather suggests the provision of tools to negotiate the contents of the package archive. Some at least partly successful solutions have already been implemented:

Search Tools There are several search mechanisms, both inside and outside of $\mathrm{R}$, that help users to locate resources - for example, the help.search and RSiteSearch commands in R; various search sites, such as http://www. rseek.org/; the sos package (Graves et al., 2009); and the Crantastic web site, http:// crantastic.org/, which has both package search and tagging features. My experience with these facilities is that they are useful, but they often both produce large numbers of irrelevant hits and miss relevant information.

Task Views The CRAN Task Views (Zeileis, 2005) are a serious attempt to help users to navigate the package system. In my opinion, the task views are valuable, but fall substantially short of providing complete and convenient access to the contents of CRAN. As I can attest from personal experience, it is difficult, for example, for maintainers of task views to keep them current. Nor are task views intended to provide a complete index to CRAN.

Keywords Help files include mandatory keywords that could, in principle, provide a basis for searching CRAN, but the standard set of keywords is not very helpful. Similarly, package 'DESCRIPTION' files have an optional Classification field that can be used to tag the package's content according to several standard schemes, but this field is little used by package authors. Similarly, $\mathrm{R}$. Rd files support optional \concept markup, which allows a package writer to supply arbitrary keywords, accessible through the help. search command. This facility too is mostly ignored. In contrast, the Bioconductor package archive takes a more sophisticated and prescriptive approach to the use of keywords, which are supplied via a mandatory biocViews field to the package 'DESCRIPTION' file. The keywords are then used to subset packages.

It is hard to imagine that, without further development, the current structure of CRAN and the tools that surround it could usefully survive, say, five more years of exponential growth. Paradoxically, then, $\mathrm{R}$ is challenged by its own success. That said, providing more effective mechanisms for organizing the information in CRAN is a difficult problem: I don't mean either to minimize the difficulty of the problem or to disparage the efforts that have been directed at it thus far.

\section{Concluding remarks}

A wild card in the future of $\mathrm{R}$ is the possible development of competing statistical software that breaks radically with the structure of the $S$ language. It is easier, however, to understand some of the social structures and processes that contribute to R's current momentum and others that present challenges to its continued development. The sum of these more predictable factors suggests that at least the shortterm prospects for the $\mathrm{R}$ Project remain bright. But, as the American baseball player Yogi Berra famously said, "It ain't over till it's over."

\section{Acknowledgments}

The research reported in this paper was supported by grants from the McMaster University Arts Research Board and the Social Sciences and Humanities Research Council of Canada. The paper is partly based on a presentation that I gave at the useR! 2008 conference in Dortmund, Germany. I am grateful to the members of R Core and others associated with the $\mathrm{R}$ Project who consented to be interviewed; to Bonnie Fox for comments on an early draft of this paper; and to two reviewers and the editor of The $\mathrm{R}$ Journal, whose critical comments on a first version of the paper stimulated various revisions. Any remaining deficiencies are, of course, my responsibility.

\section{Bibliography}

J. W. Eaton, D. Bateman, and S. Hauberg. GNU Octave. Free Software Foundation, Boston, third edition, 2008. 
K. Fogel. Producing Open Source Software. O'Reilly, Sebastopol CA, 2006.

J. Fox. An R and S-PLUS Companion to Applied Regression. Sage, Thousand Oaks CA, 2002.

J. Fox. Editorial. R News, 8(2):1-2, 2008.

S. Graves, S. Dorai-Raj, and R. Francois. sos, 2009. R package version 1.1-3.

R. Ihaka and R. Gentleman. R: A language for data analysis and graphics. Journal of Computational and Graphical Statistics, 5:299-314, 1996.

D. Knoke. Associations and interest groups. Annual Review of Sociology, 12:1-21, 1986.

F. Leisch. Sweave, part I: Mixing R and LATEX. R News, 2(3):28-31, 2002.

F. Leisch. Sweave, part II: Package vignettes. $R$ News, 3(2):21-24, 2003.

T. Lumley. biglm: bounded memory linear and generalized linear models, 2009a. R package version 0.7.

T. Lumley. survey: analysis of complex survey samples, 2009b. R package version 3.16 .

J. Pinheiro, D. Bates, S. DebRoy, D. Sarkar, and the R Core team. nlme: Linear and Nonlinear Mixed Effects Models, 2009. R package version 3.1-94.

R. D. Putnam. Bowling alone: America's declining social capital. The Journal of Democracy, 6(1):65-78, 1995.

E. Raymond. The Cathedral and the Bazaar: Musings on Linux and Open Source by an Accidental Revolutionary. O'Reilly, Sebastopol CA, 2001a.

E. Raymond. The cathedral and the bazaar:. In The Cathedral and the Bazaar: Musings on Linux and Open Source by an Accidental Revolutionary, pages 19-64. O'Reilly, Sebastopol CA, 2001b.

E. Raymond. Homesteading the noosphere. In The Cathedral and the Bazaar: Musings on Linux and Open Source by an Accidental Revolutionary, pages 65-112. O'Reilly, Sebastopol CA, 2001c.
E. Raymond. The magic cauldron. In The Cathedral and the Bazaar: Musings on Linux and Open Source by an Accidental Revolutionary, pages 113166. O’Reilly, Sebastopol CA, 2001d.

D. H. Smith. Voluntary action and voluntary groups. Annual Review of Sociology, 1:247-270, 1975.

R. M. Stallman. Free Software, Free Society: Selected Essays of Richard M. Stallman. GNU Press, Boston, 2002.

T. Therneau and T. Lumley. survival: Survival analysis, including penalised likelihood, 2009. R package version $2.35-7$.

L. Tierney. LISP-STAT: An Object-Oriented Environment for Statistical Computing and Dynamic Graphics. Wiley, New York, 1990.

A. Vance. Data analysts captivated by R's power. The New York Times, 158(54548), 2009. URL http://www.nytimes.com/2009/01/07/ technology/business-computing/07program. html?_r=2\&pagewanted=1.

W. N. Venables and B. D. Ripley. Modern Applied Statistics with S. Springer, New York, fourth edition, 2002.

S. Weber. The Success of Open Source. Harvard University Press, Cambridge MA, 2004.

S. Winchester. The Meaning of Everything: The Story of the Oxford English Dictionary. Oxford University Press, Oxford, 2003.

A. Zeileis. CRAN task views. R News, 5(1):39-40, 2005.

John Fox

Department of Sociology

McMaster University

Hamilton, Ontario, Canada

jfoxemcmaster.ca 